Karolina Tytko, Wartośc godności osoby w kontekście zależności spotecznych.

Modelowanie grafowe, [w:] Cztowiek w relacji do... Rozważania o cztowieku jako

istocie relacyjnej, red. Grzegorz Wąchol, Kraków 2020, s. 75-85.

DOI: http://dx.doi.org./10.15633/9788374388740.05

MGR KAROLINA TYTKO

\title{
Wartość godności osoby w kontekście zależności społecznych. Modelowanie grafowe
}

Powołując się na tezę o matematyczności wszechświata, jaką sformułował Michał Heller', trudno nie pokusić się o pytanie, czy obejmuje ona również niematerialne struktury dotyczące człowieka i ich własności. Mamy tu szczególnie na myśli kwestie z zakresu filozofii osoby, takie jak relacje międzyosobowe, czy godność ontologiczną osoby oraz jej uwzględnianie lub nie ${ }^{2}$.

W pierwszym odruchu można zarzucić takiemu pomysłowi jakąś próbę zamachu na humanizm (tzw. czynnik ludzki). Jednak nie podtrzymuje się tutaj czysto deterministycznego podejścia do opisu człowieka (osoby), dlatego zarzut może być przynajmniej w części odparty. Uwzględnia się z założenia wolną wolę każdego

1 Por. M. Heller, Filozoficzny program Józefa Życińskiego, „Zagadnienia Filozoficzne w Nauce” $2011 \mathrm{nr}$ 48, s. 5-22; M. Heller, Czy świat jest matematyczny?, „Zagadnienia Filozoficzne w Nauce”1998 nr 22, s. 3-14; M. Heller, Ostateczne wyjaśnienie wszechświata, Kraków 2008.

2 Por. G. Hołub, Problem osoby we wspótczesnych debatach bioetycznych, Kraków 2010; G. Hołub, Osoba w labiryncie decyzji moralnych. Bioetyka w perspektywie personalistycznej, Kraków 2014. 
człowieka w wyborze wartości godności osoby. Jest to element nieprzewidywalny (zaburzający zdeterminowany układ).

Inspiracją oraz jednocześnie poważnym argumentem za podjęciem próby modelowania matematycznego powyższych kwestii jest dynamiczny rozwój stosunkowo świeżych gałęzi nauki: socjofizyki ${ }^{3}$ i ekonofizyki ${ }^{4}$.

W niniejszym artykule podejmiemy jedynie nieśmiałą próbę opisu matematycznego wpływu osobistych wyborów dotyczących pytania: „Jak decyduję się traktować drugiego człowieka?"5 na charakterystykę zbioru osób - rozpatrzone zostanie zagadnienie zmiany ich wartości w tym zbiorze.

\section{Model matematyczny}

Ogólne zasady budowania modelu matematycznego dla wybranego zagadnienia opisane są w literaturze stosunkowo szeroko. Kierujemy się w niniejszym artykule wybranymi pozycjami ${ }^{6}$. W książce

3 Por. A. Jarynowski, Obliczeniowe nauki spoteczne w praktyce, https://www. researchgate.net/publication/271014218_Obliczeniowe_nauki_spoleczne_w_praktyce (6.03.2020).

4 Por. P. Młodzianowski, Identyfikacja praktycznych obszarów zastosowania modeli ekonofizycznych, „Zeszyty Naukowe Politechniki CzęstochowskiejZarządzanie" 1 (2017) nr 28, s. 64-78; A. Jakimowicz, Ekonofizyka jako nowa szkota myślenia ekonomicznego, w: B. Fiedor, Nauki ekonomiczne. Stylizowane fakty a wyzwania wspótczesności, Warszawa 2015, s. 103-115.

5 Chodzi przede wszystkim o rozróżnienie: czy traktuję drugiego jak środek do celu, czy szanuję go jako cel sam w sobie. Por. G. Hołub, Problem osoby..., dz. cyt.

6 Zob. V. Mityushev i in., Metody komputerowe matematyki przemystowej, cz. 1, Matematyczne modelowanie i symulacje komputerowe, Gliwice 2010; V. Mityushev, W. Nawalaniec, N. Rylko, Introduction to Mathematical Modeling and Computer Simulations, Boca Raton 2018. 
Vladymira Mityusheva, Wojciecha Nawalańca oraz Natalii Rylko Introduction to Mathematical Modeling and Computer Simulations przedstawiony jest model grafowy, który opisuje i analizuje zjawisko mechanicznych oddziaływań składowych materiału kompozytowego.

\section{I. OGÓLNE ZAŁOŻENIA MODELU MATEMATYCZNEGO}

1) Zakłada się pewien determinizm mechanizmów społecznych i biologiczno-psychologicznych dla ustalonego zbioru osób w danym przedziale czasowym ${ }^{7}$. To znaczy, że przyjmuje się, iż dynamika zmian w zbiorze wartości materialnych tych osób jest opisana pewnym układem dynamicznym ${ }^{8}$. Oczywiście nie zamierzamy nikogo zapewniać, że znamy wszystkie zmienne ${ }^{9}$ wszystkich

7 Por. z definicją: S. Mazierski, S. Zięba, Determinizm, http://www.ptta.pl/ pef/pdf/d/determinizm.pdf (16.11.2019). Przeciwieństwem determinizmu jest indeterminizm.

8 Propozycję stworzenia modelu dla społeczeństwa przedstawił już w 1651 roku Thomas Hobbes w dziele Lewiatan. Jak pisze Piotr Nyczka: „Postrzegał on człowieka, a także społeczeństwo jako mechanistyczny twór balansujący między wolnością/brakiem bezpieczeństwa a podporządkowaniem/bezpieczeństwem. Uważal, że bez ustanowienia państwa i prawa każdy będzie walczyć z każdym, egoistycznie dążąc do spełnienia swoich osobistych celów, zagrażając przy tym bezpieczeństwu innych”. Później ten pomysł został wykorzystany przez Johna Nasha, który rozwinął tę koncepcję i przekształcił ją w prawo nazywane „równowagą Nasha”. Por. P. Nyczka, Przejscia fazowe w uogólnionym modelu q-wyborcy na grafie zupetnym, praca doktorska, Uniwersytet Wrocławski, Wydział Fizyki i Astronomii, Wrocław 2014.

9 Por. T. Pabjan, Gottfrieda W. Leibniza idea świata najlepszego z możliwych, „Studia z Historii Filozofii” 8 (2017) nr 4, s. 107-124. Według Leibniza tylko Bóg zna wszystkie możliwe stany Wszechświata i wybiera najlepsze. 
możliwych układów równań opisujących zarówno życie każdego człowieka, jak również oddziaływania międzyludzkie. Będziemy rozpatrywać przykładowe ich stany i traktować wartości przypisane każdej osobie w danym momencie jako „dane”, a nie jako funkcję.

2) Na dany stan nakłada się wybierane przez każdą osobę wartości godności (w sposób, jaki zaraz pokażemy). Każda osoba wybiera jedną z dwóch (dla uproszczenia) możliwości - tj. pewne 0 lub wartość nieskończoną (symboliczny zapis możliwości wyboru afirmacji godności osoby bądź braku jej afirmacji $\left.{ }^{10}\right)$. Jest to element indeterministyczny.

\section{I.2. PODSTAWOWE OZNACZENIA W MODELU}

Zgodnie z książką Graphs and Geometry Lászla Lovásza wykorzystujemy pojęcia teorii grafów ${ }^{11}$. Weźmy $X-$ zbiór $n$ osób $(n=\in \mathrm{N})$. Rozpatrujemy stan układu dynamicznego ${ }^{12}$, w którym $f_{1}, f_{2}, \ldots, f_{n}$ - to wartości materialne wyznaczone dla każdej osoby (wierzchotka) w chwili $t$ przez pewne funkcje $f_{n}\left(\operatorname{tr}\left(f_{n 0}, t\right)\right)^{13}$ zależne od czasu, warunków początkowych i „trybu

10 Por. K. Kaczmarczyk, Substytucja Lévinasa-substancjalna stużba innemu?, „Logos i Ethos” 41 (2016) nr 1, s. 7-34.

11 Por. L. Lovász, Graphs and Geometry, Budapest 2010, http://web.cs.elte.hu / lovasz/bookxx/geomgraphbook/geombook2019.01.11.pdf(6.03.2020).

12 „Przez układ dynamiczny rozumiemy przestrzeń fazową $X$ wraz z zadaną regułą ewolucji stanów $x \in X \mathrm{w}$ czasie $t$ ". J. Banasiak, Chaotyczne liniowe uktady dynamiczne. Teoria $i$ zastosowania, „Roczniki Polskiego Towarzystwa Matematycznego. Seria 2: Wiadomości Matematyczne” 41 (2005), s. 53.

13 Nie będziemy się jednak zajmować na łamach niniejszego artykułu układem dynamicznym, a tylko pewnym jego stanem, w którym interesują nas jedynie wyznaczone dla stanu określone wartości „materialne” osób $x$ ze zbioru $X$. 
życia” - tr; $f_{n 0}$ - wartość materialna początkowa (zadana) dla osoby $n$.

Innymi słowy - przyjmujemy, że wartość „materialną” każdej osoby w całym jej życiu określa pewna charakterystyczna dla niej funkcja. Na pewno jest uzależniona od warunków początkowych tej osoby, od czasu, a przy wzięciu pod uwagę doświadczenia potocznego - również od stosunku pracy do konsumpcji (czynnik wewnętrzny) oraz od pewnych nieoczekiwanych zdarzeń niezależnych od osoby (czynnik zewnętrzny): pozytywnych (zwiększających wartość materialną) bądź negatywnych (zmniejszających wartość materialną) $)^{14}$.

Dodatkowo dla każdej krawędzi możemy wyznaczyć $\mu_{\mathrm{ij}}$ - wagę relacji pomiędzy osobami $i$ oraz $j$ (krawędzi). Przyjmujemy, że jest ona odwrotnie proporcjonalna do różnicy $\left|f_{i}-f_{j}\right|$, tzn. jeśli $\left|f_{i}-f_{j}\right|=0$, waga $\mu_{\mathrm{ij}}=1$, jeśli $\left|f_{i}-f_{j}\right| \neq 0=>$ im jest większa, tym mniejsza waga relacji.

Graf to zbiór wierzchołków połączonych krawędziami $G=(V, E)$. Możemy przypisywać wartości do krawędzi grafu, jak na poniższym rysunku:

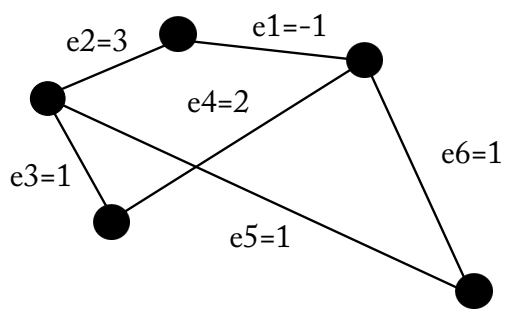

Rys. 1. Przykładowy graf $z$ ważonymi krawędziami, opracowanie własne

14 Mówiąc o wartości materialnej, mamy na myśli nie tylko finanse i posiadane dobra w ścisłym sensie materialne - bierzemy również pod uwagę zdrowie, intelekt, poważanie społeczne itd. 
Możemy również przypisywać dane do wierzchołków grafu:

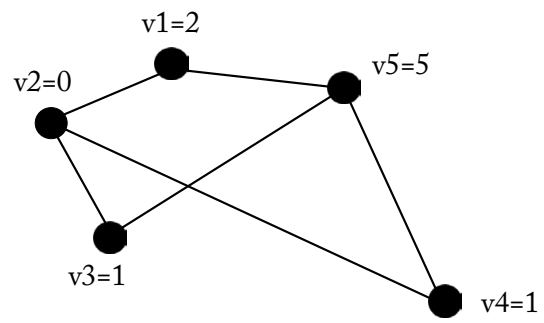

Rys. 2. Przykładowy graf z ważonymi wierzchołkami, opracowanie własne

Przedstawmy powyższe zagadnienie w postaci grafu nieskierowanego, który zawiera $n=4$ wierzchołki oraz krawędzie pomiędzy niektórymi z nich. Wierzchołki oznaczają odpowiednio osoby, krawędzie - relacje między poszczególnymi osobami. Możemy przyjąć, że na każdym wierzchołku $a_{i}$ mamy opisaną wartość $f_{i}$, a na każdej krawędzi wartość $\mu_{\mathrm{ij}}=\mu_{\mathrm{ji}}$ (jeśli graf skierowany, w innym przypadku musielibyśmy/moglibyśmy rozróżnić te dwie wagi).

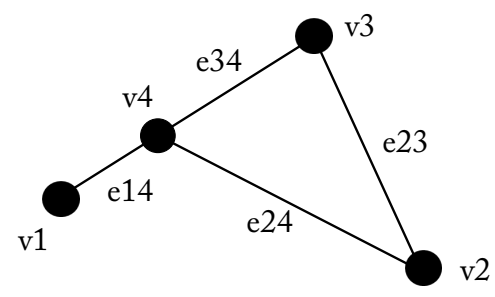

Rys. 3. Przykładowy graf z oznaczonymi wierzchołkami i krawędziami, opracowanie własne

Macierz sąsiedztwa dla tego grafu wygląda następująco - wierzchołki $\times$ wierzchołki (zakładamy, że osoba jest zawsze ze sobą samą $\mathrm{w}$ relacji, i przyjmujemy wtedy oznaczenie 1 ): 


$$
\left(\begin{array}{llll}
1 & 0 & 0 & 1 \\
0 & 1 & 1 & 1 \\
0 & 1 & 1 & 1 \\
1 & 1 & 1 & 1
\end{array}\right)
$$

Dla grafu ważonego będziemy mieć odpowiednią macierz:

$$
W=\left(\begin{array}{cccc}
1 & 0 & 0 & \mu_{14} \\
0 & 1 & \mu_{27} & \mu_{24} \\
0 & \mu_{32} & 1 & \mu_{34} \\
\mu_{41} & \mu_{42} & \mu_{43} & 1
\end{array}\right)
$$

Natomiast macierz incydencji dla grafu wygląda tak - wierzchołki $\times$ krawędzie (tu akurat będzie $4 \times 4$, ale nie zawsze jest wymiaru $n \times n)$, jeśli $v_{12}=v_{1}, v_{24}=v_{2}, v_{23}=v_{3}$ i $v_{34}=v_{4}$, to:

$$
\left(\begin{array}{llll}
1 & 0 & 0 & 1 \\
0 & 1 & 1 & 0 \\
0 & 0 & 1 & 0 \\
1 & 1 & 0 & 1
\end{array}\right)
$$

A gdy chcemy uwzględnić wartości $f$, to mamy następujący graf ważony:

$$
F=\left(\begin{array}{cccc}
f_{1} & 0 & 0 & 0 \\
0 & f_{2} & 1 & 1 \\
0 & 1 & 1 & 1 \\
1 & 1 & 1 & 1
\end{array}\right)
$$




\section{Funkcja wartości godności}

Spróbujemy teraz utworzyć model grafowy dla zagadnienia wartości godności w kontekście zależności społecznych. Podstawową ideą modelowania $\mathrm{w}$ niniejszym artykule są następujące zasady:

- każdy wierzchołek z zadaną wartością oznacza osobę z zadaną „pozycją społeczną”, tj. porównywalną między sobą wartością materialną;

- każda krawędź z zadaną wartością (wagą) oznacza relację międzyosobową z określonymi jej „parametrami”, tj. cechami, które pozwalają na porównywanie: relacja silniejsza i słabsza.

Przechodząc teraz do formalnego opisu, wprowadźmy zbiór funkcji $G:=\left\{g_{n}\left(f_{1}, f_{2}, \ldots, f_{n}\right):=\left(g_{n}\left(f_{1}\right), g_{n}\left(f_{2}\right), \ldots, g_{n}\left(f_{n}\right)\right)\right\}$, tj. zbiór takich funkcji, które przypisują wartości godności osoby wybrane przez każdą osobę każdej osobie. Otrzymujemy macierz przekształcenia liniowego (macierz godności):

$$
G=\left(\begin{array}{llll}
g_{1}\left(f_{1}\right) & g_{2}\left(f_{1}\right) & g_{3}\left(f_{1}\right) & g_{4}\left(f_{1}\right) \\
g_{1}\left(f_{2}\right) & g_{2}\left(f_{2}\right) & g_{3}\left(f_{2}\right) & g_{4}\left(f_{2}\right) \\
g_{1}\left(f_{3}\right) & g_{2}\left(f_{3}\right) & g_{3}\left(f_{3}\right) & g_{4}\left(f_{3}\right) \\
g_{1}\left(f_{4}\right) & g_{2}\left(f_{4}\right) & g_{3}\left(f_{4}\right) & g_{4}\left(f_{4}\right)
\end{array}\right)
$$

Zauważmy, że dla rozpatrywanego przez nas przykładowego grafu macierz przekształceń wygląda następująco:

$$
G(F)=\left(\begin{array}{cccc}
g_{1}\left(f_{1}\right) & 0 & 0 & g_{4}\left(f_{1}\right) \times \mu_{14} \\
0 & g_{2}\left(f_{2}\right) & g_{3}\left(f_{2}\right) \times \mu_{23} & g_{4}\left(f_{2}\right) \times \mu_{24} \\
0 & g_{2}\left(f_{3}\right) \times \mu_{32} & g_{3}\left(f_{3}\right) & g_{4}\left(f_{3}\right) \times \mu_{34} \\
g_{1}\left(f_{4}\right) \times \mu_{41} & g_{2}\left(f_{4}\right) \times \mu_{42} & g_{3}\left(f_{4}\right) \times \mu_{43} & g_{4}\left(f_{4}\right)
\end{array}\right)
$$




\section{Opis funkcji $g_{i}\left(f_{i}\right)$ i zastosowanie}

Wprowadza się oznaczenia:

$$
g_{i}\left(f_{j}\right):=\left\{\begin{array}{l}
\omega f_{j}, \text { gdy osoba } i \text { uwzględnia godność osoby w relacji } \\
\mathrm{z} \text { każdą osobą } j \in(1, \ldots, n), \\
r f_{j}, \text { gdy osoba } i \text { nie uwzględnia godności osoby w re- } \\
\text { lacji z każdą osobą } j \in(1, \ldots, n),
\end{array}\right.
$$

$\omega, r$ - wybrane wartości godności osoby przez osobę $i$,

$\omega$ - liczba nieskończenie duża, taka, że $\forall m \in N, m f_{n}<\omega f_{n}$, natomiast $r$ - liczba skończona $(r \in R)$.

Rozpatrzmy przypadek: mamy w danym układzie dynamicznym stan, w którym przynajmniej jedna osoba ma wartość $f_{i}$ nieskończenie małą - innymi słowy jest „wykluczona” społecznie (tj. ma taką wartość $f_{i}$, że dla każdego $n \in N n f_{i}<1$ ).

Jeśli dla uproszczenia przyjmiemy, że $f_{i}=b /{ }_{\omega}$ oraz minimum jedna osoba j przyjmuje nieskończoną wartość godności, to mamy: $g_{j}\left(f_{i}\right)=\mathrm{b}$.

\section{Podsumowanie}

W niniejszym opracowaniu próbowano modelować matematycznie kwestię godności osoby w kontekście zależności społecznych (relacji międzyosobowych w danym zbiorze osób). Przypomnijmy - chodziło o pytanie: "Jak decyduję się traktować drugiego człowieka?”. A szerzej: „Jaki mają wpływ osobiste wybory wartości godności na wartości życia ludzi w danej grupie?”. Został opracowany model statyczny abstrakcyjnej grupy społecznej. W dalszych opracowaniach model statyczny będzie rozwijany w dynamiczny 
według metody przedstawionej w książce Introduction to Mathematical Modeling and Computer Simulations ${ }^{15}$.

W opisanym przykładzie podczas analizy sytuacji osoby $i$ wykluczonej społecznie mającej relację $z$ osobą $j$ wybierającą nieskończoną wartość godności otrzymaliśmy w wektorze wartości względnych życia wyraz różny od dążącego do 0 (w wektorze $\left(g_{2}\left(f_{i}\right), g_{2}\left(f_{i}\right), \ldots, g_{n}\left(f_{i}\right)\right)$, mamy wyraz $\left.g_{j}\left(f_{i}\right)=b \in R\right)$. Oznacza to potencjalną zmianę statusu osoby wykluczonej na przynależącą do społeczeństwa.

Artykuł jest wynikiem badań zrealizowanych w ramach tematu Nieskończonośc i nieskończenie mate w matematyce a filozofia osoby, które zostały sfinansowane $z$ dotacji celowej na naukę przyznanej przez MNiSW w roku 2018.

\section{Wybrana bibliografia}

1. Banasiak J., Chaotyczne liniowe uktady dynamiczne. Teoria $i z a-$ stosowania, „Roczniki Polskiego Towarzystwa Matematycznego. Seria 2: Wiadomości Matematyczne” 41 (2005), s. 51-79.

2. Heller M., Czy świat jest matematyczny?, „Zagadnienia Filozoficzne w Nauce" 1998 nr 22, s. 3-14.

3. Heller M., Filozoficzny program Józefa Życińskiego, „Zagadnienia Filozoficzne w Nauce” 2011 nr 48, s. 5-22.

4. Heller M., Ostateczne wyjaśnienie wszechśrwiata, Kraków 2008.

5. Hołub G., Osoba w labiryncie decyzji moralnych. Bioetyka wperspektywie personalistycznej, Kraków 2014.

6. Hołub G., Problem osoby we wspótczesnych debatach bioetycznych, Kraków 2010.

15 Por. V. Mityushev, W. Nawalaniec, N. Rylko, Introduction to Mathematical..., dz. cyt. 
7. Jakimowicz A., Ekonofizyka jako nowa szkota myślenia ekonomicznego, w: B. Fiedor, Nauki ekonomiczne. Stylizowane fakty a wyzwania wspótczesności, Warszawa 2015, s. 103-115.

8. Jarynowski A., Obliczeniowe nauki spoteczne w praktyce, https:// www.researchgate.net/publication/271014218_Obliczeniowe_ nauki_spoleczne_w_praktyce (6.03.2020).

9. Kaczmarczyk K., Substytucja Lévinasa - substancjalna stużba innemu?, „Logos i Ethos” 41 (2016) nr 1, s. 7-34.

10. Lovász L., Graphs and Geometry, Budapest 2010, http:// web.cs.elte.hu/ lovasz/bookxx/geomgraphbook/geombook2019.01.11.pdf (6.03.2020).

11. Mazierski S., Zięba S., Determinizm, http://www.ptta.pl/pef/ $\mathrm{pdf} / \mathrm{d} /$ determinizm.pdf (16.11.2019).

12. Mityushev V., Nawalaniec W., Rylko N., Introduction to Mathematical Modeling and Computer Simulations, Boca Raton 2018.

13. Mityushev V.i in., Metody komputerowe matematyki przemystowej, cz. 1, Matematyczne modelowanie i symulacje komputerowe, Gliwice 2010.

14. Młodzianowski P., Identyfikacja praktycznych obszarów zastosowania modeli ekonofizycznych, „Zeszyty Naukowe Politechniki Częstochowskiej - Zarządzanie" 1 (2017) nr 28, s. 64-78.

15. Nyczka P., Przejścia fazowe w uogólnionym modelu q-wyborcy na grafie zupetnym, praca doktorska, Uniwersytet Wrocławski, Wydział Fizyki i Astronomii, Wrocław 2014.

16. Pabjan T., Gottfrieda W. Leibniza idea świata najlepszego z możliwych, „Studia z Historii Filozofii” 8 (2017) nr 4, s. 107-124. 
A/4 Uniwersytet Papieski

Tfon Jana Pawla II 